\title{
SOME EFFECTS OF DWARF MISTLETOE ON WESTERN HEMLOCK ${ }^{1}$
}

\author{
By R. W. WELLWOOD ${ }^{2}$
}

Born in Victoria, B.C., 1912; 1935, B.A.Sc., U.B.C. in Forest Engineering; 1938, M.F., Duke University, Durham, N.C.; 1943, Ph.D., Duke University, Durham N.C.; Field experience with B.C. Forest Service, Victoria Lumber and Manufacturing Co. Ltd., and Lake Logging Co. Ltd.; June, 1943-July, 1946, Wood Technologist, Commonwealth Plywood Co. Ltd., Ste. Therese, P.Q.; July, 1946-to date, Dept. of Forestry, and Faculty of Forestry, U.B.C., present rank: Professor. Member of the Board of Examiners, Association of Professional Engineers of British Columbia. Vice-Chairman, Pacific Northwest Section, Forest Products Research Society.

Acknowledgement is made to the various students who assisted with laboratory work, and to the late Dr. D. C. Buckland for a critical review of the paper. Funds were provided by research grants from the University of British Columbia.

\section{INTRODUCTION}

Stands of western hemlock (Tsuga heterophylla (Raf.) Sarg.) are frequently plagued with dwarf mistletoe (Arceuthobium campylopodum forma tsugensis (Rosend) Gill), whose presence is observed in the form of large club-like brooms of living (or dead) branches, enlarged branch stubs, and stems malformed by cankers (See Fig. 1). References that relate to the effect of this parasite on both rate of growth and wood characteristics are infrequent in the literature. In a comprehensive article by Buckland and Marples (3), the writers consider the effect of dwarf mistletoe on mature hemlock stands and suggest suitable practices to overcome the disease in a managed forest.

On the University Research Forest at Haney, B.C., stands containing western hemlock are typical of those on many areas of the Lower Coast, where the disease is common. One particular area appeared so badly infected that it was decided to clear cut and establish a new stand. Approximately 10 acres of merchantable hemlock and balsam fir were logged during 1953. From this area sufficient material was collected for a preliminary study of the effect of the disease upon the characteristics of tree growth. A forest pathologist ${ }^{3}$ cooperated in the selection of sample trees and the description of visual characteristics.

\section{STAND History}

In 1867 a fire burned over much of the University Forest, killing most of the timber. Excepting a few veteran cedar and Douglas fir, any live individuals remaining apparently were advanced reproduction or suppressed understory trees of hemlock and balsam fir. Only in isolated places in the forest did these understory trees survive. Where hemlock and balsam fir have re-

\footnotetext{
${ }^{1}$ Research Paper No. 13, Faculty of Forestry, University of British Columbia. Submitted for publication November 10, 1955.

2 Professor, Faculty of Forestry University of British Columbia.

${ }^{3}$ Mr. A. C. Molnar, Forest Biology Division, Canada Science Service, assisted in selecting the trees and identifying fungi.
} 
covered from their original suppression to become the main stand, the hemlock is almost universally infected with dwarf mistletoe. The parasite has also spread to hemlock in the 80 -year-old reproduction.

\section{Material}

Ten standing trees were selected for study. (See Table 1.) Four of these showed severe attack by mistletoe, with large witches' brooms throughout the living crown. Three of these four had prominent stem swellings (often referred to as "burls") and one of them had top die-back, a characteristic of mistletoe infection $(2,3)$. Three other trees were moderately infected, in that brooms were common in the lower crowns, but the upper crowns were full and normal; no stem swellings were present. Three trees had either no visible infection (a rarity in the area) or only a few small brooms in the lower crowns, and were classed as "lightly infected."

Diameters (breast height) ranged from 27.8 in. to 38.4 in., and ages from 146 years (stump height) to 256 years. The diameter-age relationship was weak, as would be expected for a tolerant species. In some instances the central core contained rot so that total age was interpolated. Site index was about 140 according to the western hemlock tables (1).

Trees were felled and bucked into 16-foot logs. Discs were removed at these intervals, to provide stem analysis data and material for study of the wood. Further cuts were made at specified points to determine the effects of swellings or of large witches' brooms. The discs were further reduced to wedges or segments, taken along radii, to include normal wood, and where present, wood close to an abnormality (limb having a witches' broom, or stem swelling). Smaller samples, in addition to these, also were removed from the outer two inches of sapwood.

Standard procedures were used to determine moisture content of the pieces, and specific gravity based on oven-dry weight and volume. It would have been desirable to have followed typical logs through a sawmill to determine grade and volume recoveries, but this was not feasible at the time.

\section{A. On Rate of Growth}

\section{EFFECT OF Mistletoe}

\section{Results.}

Standard stem analysis procedures established rates of diameter and height growth. Volumes were computed for the time of cutting and for each decade of the past 100 years (i.e. 1953, 1943 ... 1853). The most obvious effect of the mistletoe would be to reduce the vigor of the tree, which would show in an analysis of decadal volume growth.

Where all data within each group are pooled, the result is somewhat misleading since volume is directly correlated with diameter and since a range of diameters was included. Figure 3 shows the results obtained by grouping trees of comparable diameters. It is seen that the lightly infected trees (Fig. 3a) have the greatest decadal growth over the past 50 years, but that growth of the moderately infected trees was similar over much of the past century. The severely infected trees (Fig. 3a) were growing well until about 50 years ago, but since then their rate of growth has decreased rapidly.

Growth of tree 11 (lightly infected) is compared with that of trees 3 


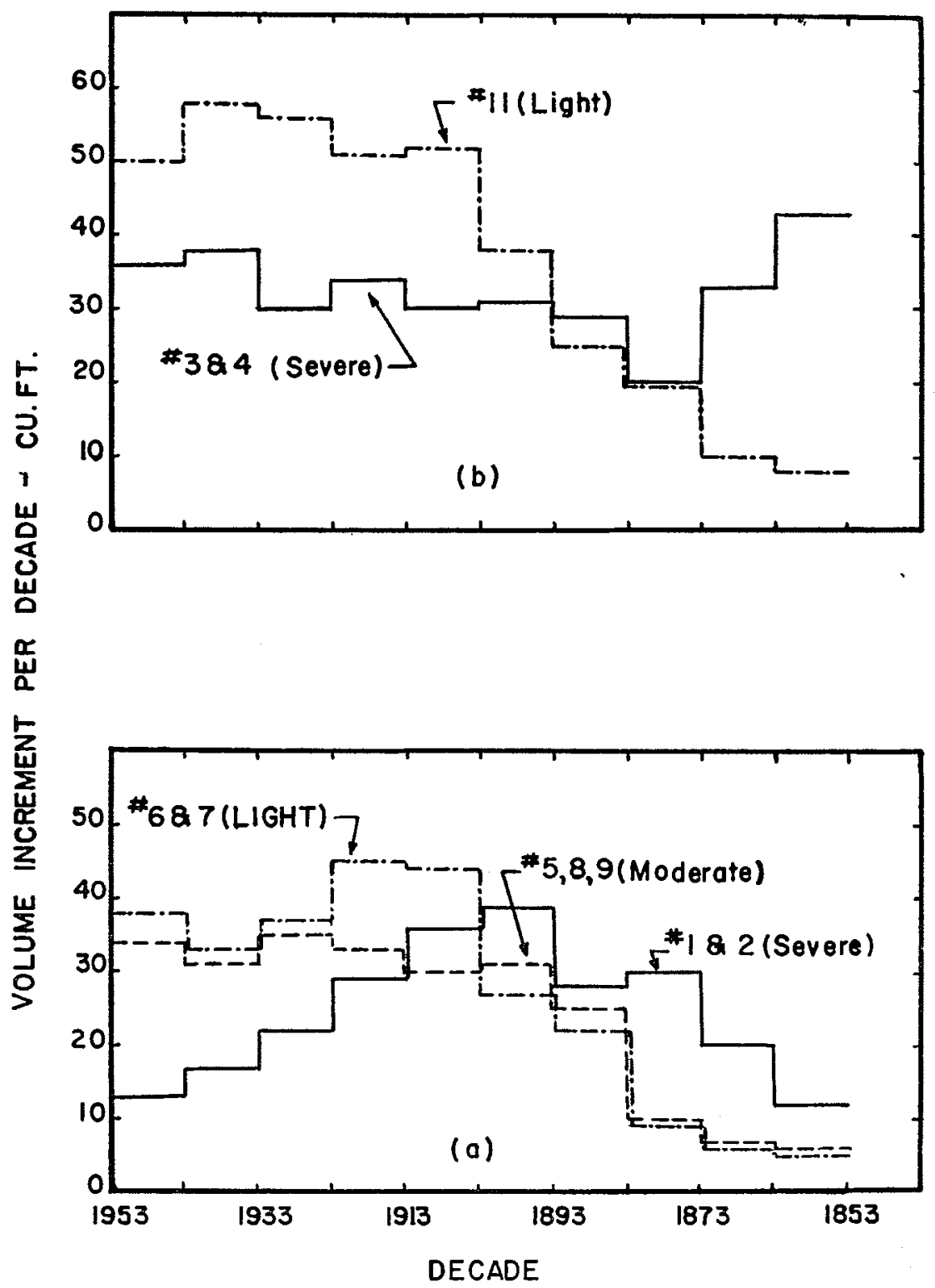

Fig. 3. Volume increment per decade (cubic feet) for trees of light, medium(moderate) and severe infection with hemlock mistletoe, segregated by diameter groups $(a)$ and (b). 
SEPTEMBER, 1956

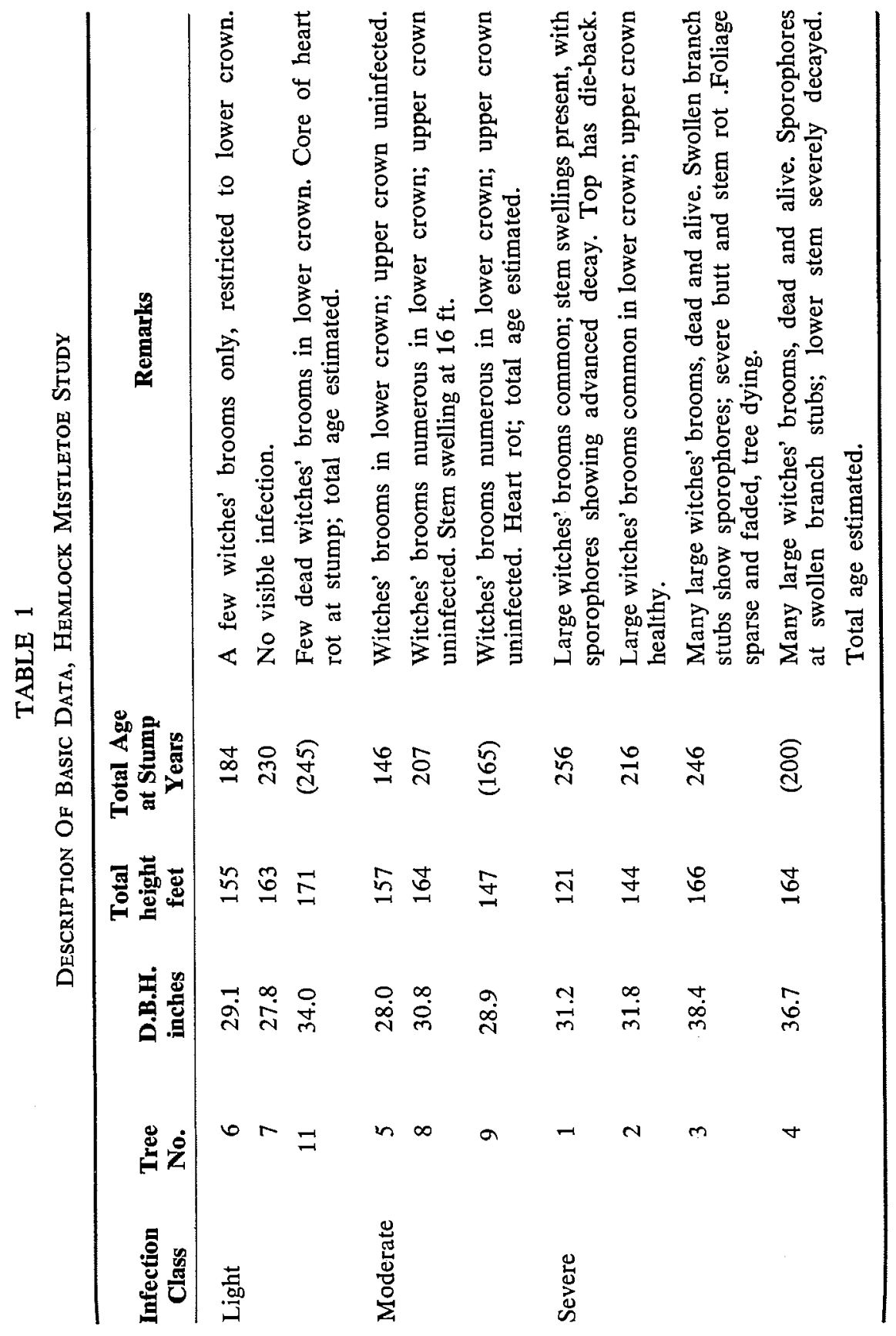


and 4 (severely infected) in Figure 3 (b). The effect of the mistletoe would seem apparent. Tree 11, although of lesser diameter than the others, was growing much faster. A confounding factor was that trees 3 and 4 had severe heart rot also and, in fact, for much of their length were mere shells of living sapwood over a punky core. Here, mistletoe could not be accountable for all growth retardation. Sten cankers and dead stubs of broomed branches were, however, the apparent means of entry for the pathogens, and thus were accountable for the internal condition of these trees if not for the lack of growth vigor.

Another method of comparing growth would be to express decadal volume increase as a percentage of tree volume at the start of the decade. Data were arranged in this way and plotted (Figure 4). Since a large tree is unlikely to increase its percentage volume at the same rate as a smaller tree, present diameter again is used to classify the data. The differences are apparent, with the severely infected trees showing the lowest percentage volume growth, and the other two groups being similar to one another.

\section{Conclusions.}

(a) Moderate infection by dwarf mistletoe, i.e. witches' brooms in the lower crown, has no serious effect on tree vigor.

(b) Severe infection, as characterized by numerous, large brooms in the crown, has a serious effect on tree vigor.

(c) Although mistletoe brooms affect tree vigor, they are not the apparent direct cause of tree death. They do reduce the tree's resistance to insect attack $(2,3)$ and may cause die-back of the top $(2,3)$. The large branch stubs resulting from the witches' brooms and stem swellings, are avenues of entry for fungi.

(d) Silvicultural measures to remove mistletoe from hemlock stands would prove difficult but would be desirable (3).

The above conclusions are based on only a few samples, from a limited area, but would seem to apply generally to this parasite and correspond with the findings of Buckland and Marples (3).

\section{B. On Specific Gravity and Moisture Content}

1. Results.

The outward characteristics of dwarf mistletoe (witches' brooms, stem swellings) indicate an inward effect on the tree. Stem analysis sections and special cuts made for observations reveal a number of interesting features.

(a) Stem Swellings.

Although stem swellings occur only in localized areas, they have a marked effect on the wood therein. This is well illustrated in Figure 2, where cuts through large swellings show the callus tissue, included bark, normal wood and a zone of decay that has entered through the branch stub.

(b) Witches' Brooms.

Physical weight of these brooms, sometimes several hundred pounds (3), must require strengthening tissue in the branches supporting them, and in the stem. The characteristic form of stem at a broomed limb is shown in Figure 5. The knot is extremely hard and dense, slowing the bucking in the woods and 


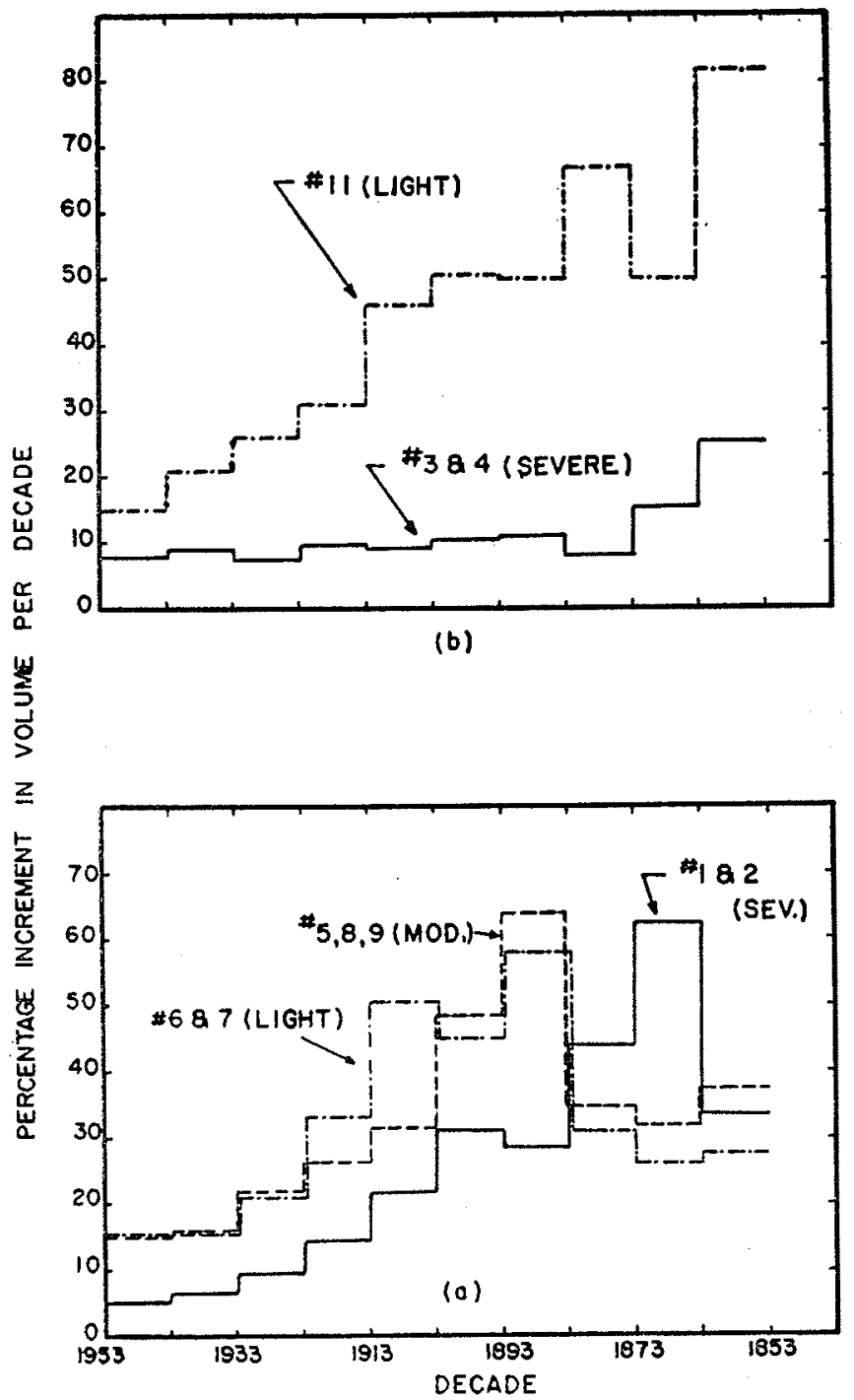

Fig. 4. Percentoge Increment in volume per decode for trees of light, moderote ond severe infection with hemlock mistlotoe, segregated by diometer groups (a) and (b). 
dulling the saw teeth in that operation and later in the sawmill. In addition the stem is not circular and the heart is off-centre. It will be shown that wood properties are affected.

Figure 6 shows the effect on a stem where three brooms are supported at the same level. Little lumber of worthwhile grade or value would be recovered in this part of the stem, and pulp yield would be low due to the extreme size of the knots.

(c) Specific Gravity or Wood Density.

Witches' brooms affect the physiology of the tree because of their weight and their water demands. One would expect denser or compression wood to develop on the side of the stem nearest the limbs supporting the brooms. This is shown in Table 2, where a comparison is made between the specific gravity of sections adjacent to and opposite from mistletoe infection. It is seen that in most cases the wood is denser on the side nearest the parasite. A statistical test of the difference between paired samples shows that these differences are significant and not due to chance. In Table 3 are shown the specific gravity data for each tree, based on normal wood only, at its respective height in the stem. Results for both the lightly and moderately infected trees are similar, and are pooled. These data are plotted in Figure 7 which shows the relation between specific gravity and height in the stem for whole sections and for the outer sapwood only. The lower values for the severely infected trees are apparent. They cannot be attributed only and directly to the mistletoe since these trees are severely infected with wood destroying fungi. The mistletoe, however, did provide an avenue of entry for the fungi .

(d) Moisture Content.

The demand of the mistletoe for water is shown when a comparison is made of the moisture contents of wood samples adjacent to and opposite from infected limbs. In Table 4 are shown the moisture contents for the appropriate sections. The lower moisture contents on the mistletoe sides are obvious for both the whole sections and the sapwood only. A test of the differences shows them as significant.

In Table 5 moisture contents are shown for each section, and these are plotted in their appropriate groupings in Figure 8. The difference between the major groups is obvious, but again the differences are in part related to the fungi and not alone to the mistletoe.

\section{Conclusions.}

(a) Moderate infection by dwarf mistletoe has no serious effect on the physiology of the tree.

(b) Severe infection has a serious effect on wood density.

In trees that are severely infected the average specific gravity of the wood is lower than in uninfected trees, suggesting lower strength properties and a lower pulp yield. In addition, trees that are severely infected have bigher specific gravity on the side nearest the infection than on the opposite side. Variable density within one board is a major cause of warping in lumber.

(c) Severe infection has a marked effect on moisture content of the wood. 


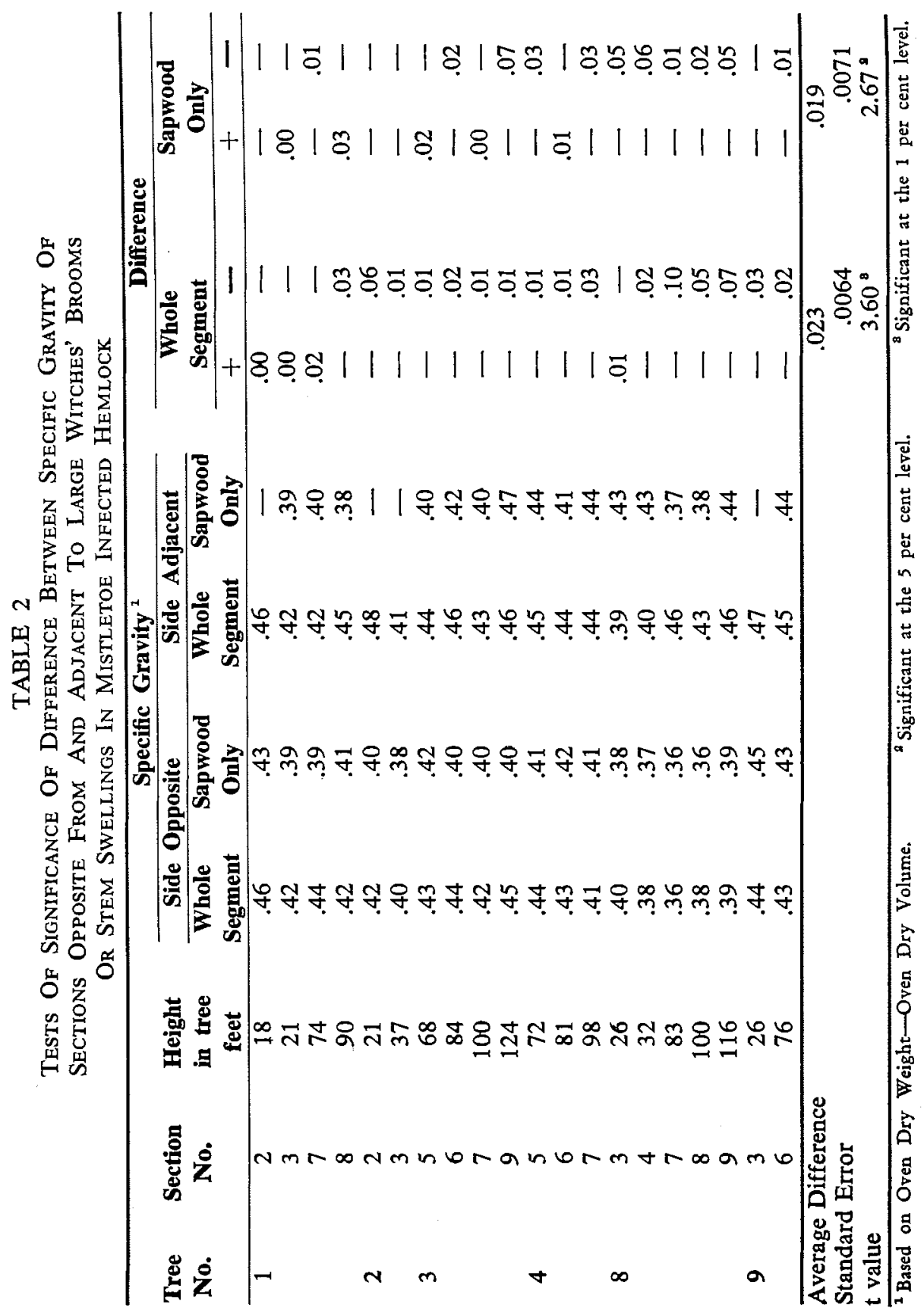




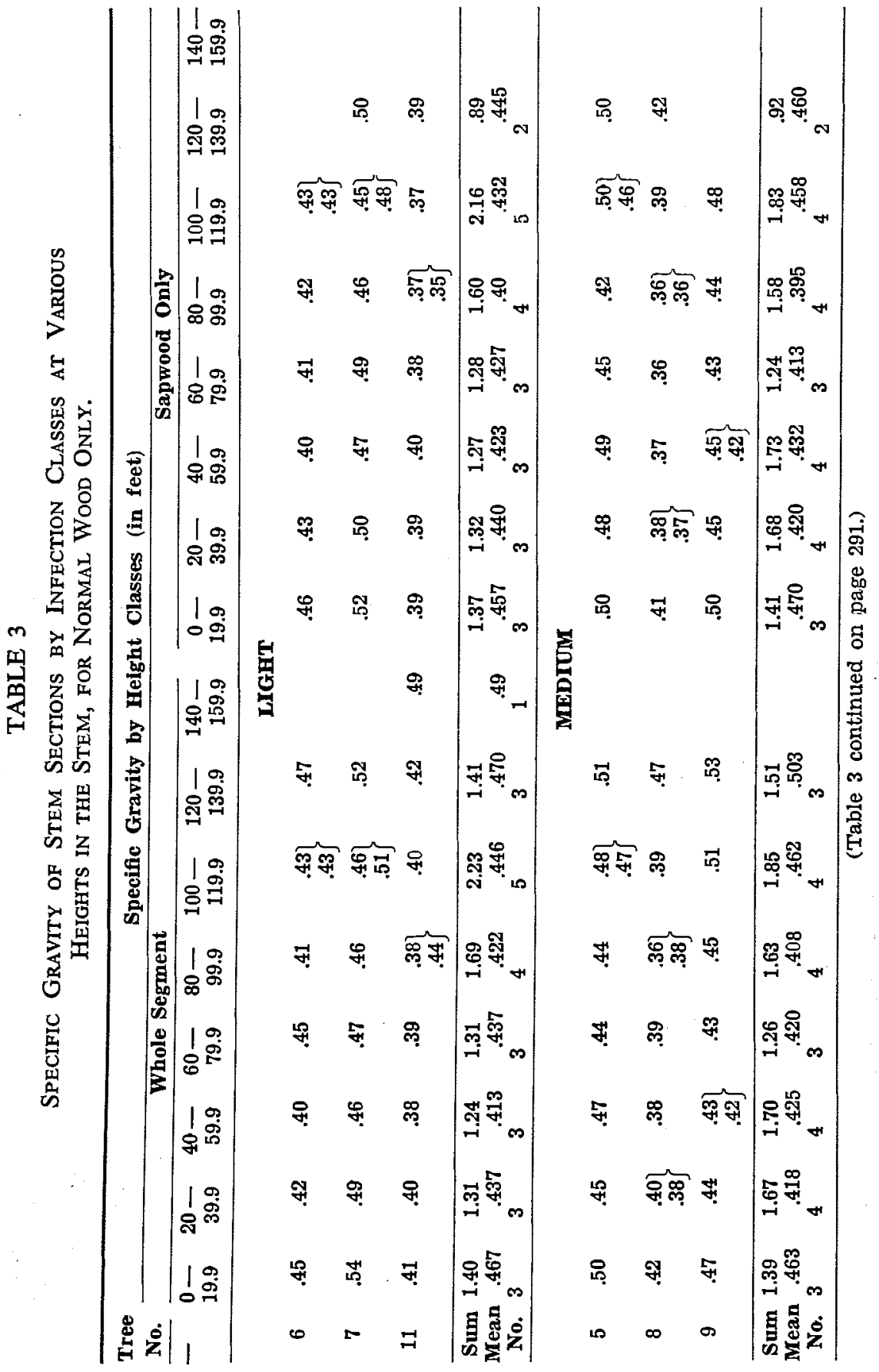


SEPTEMBER, 1956

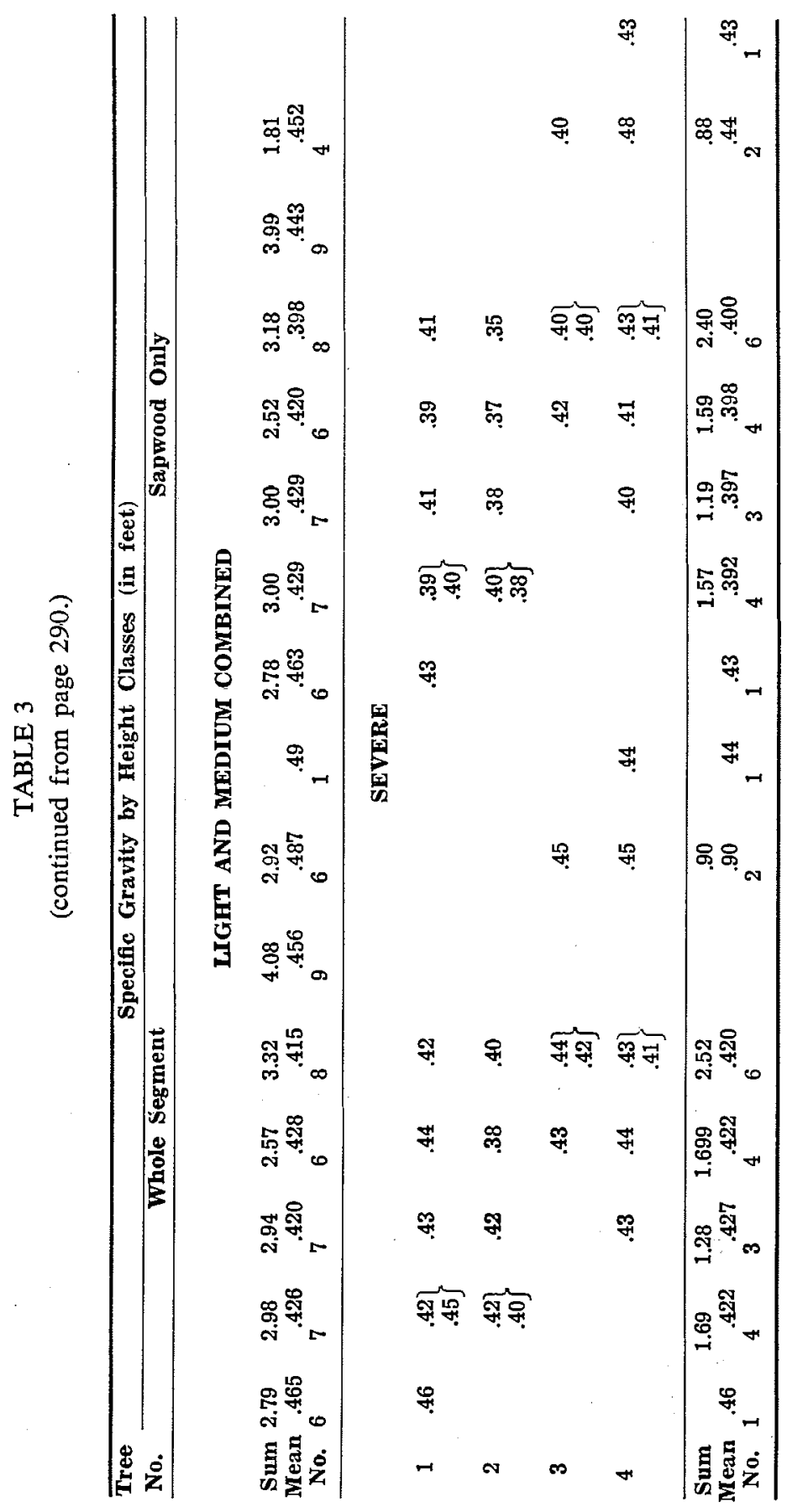




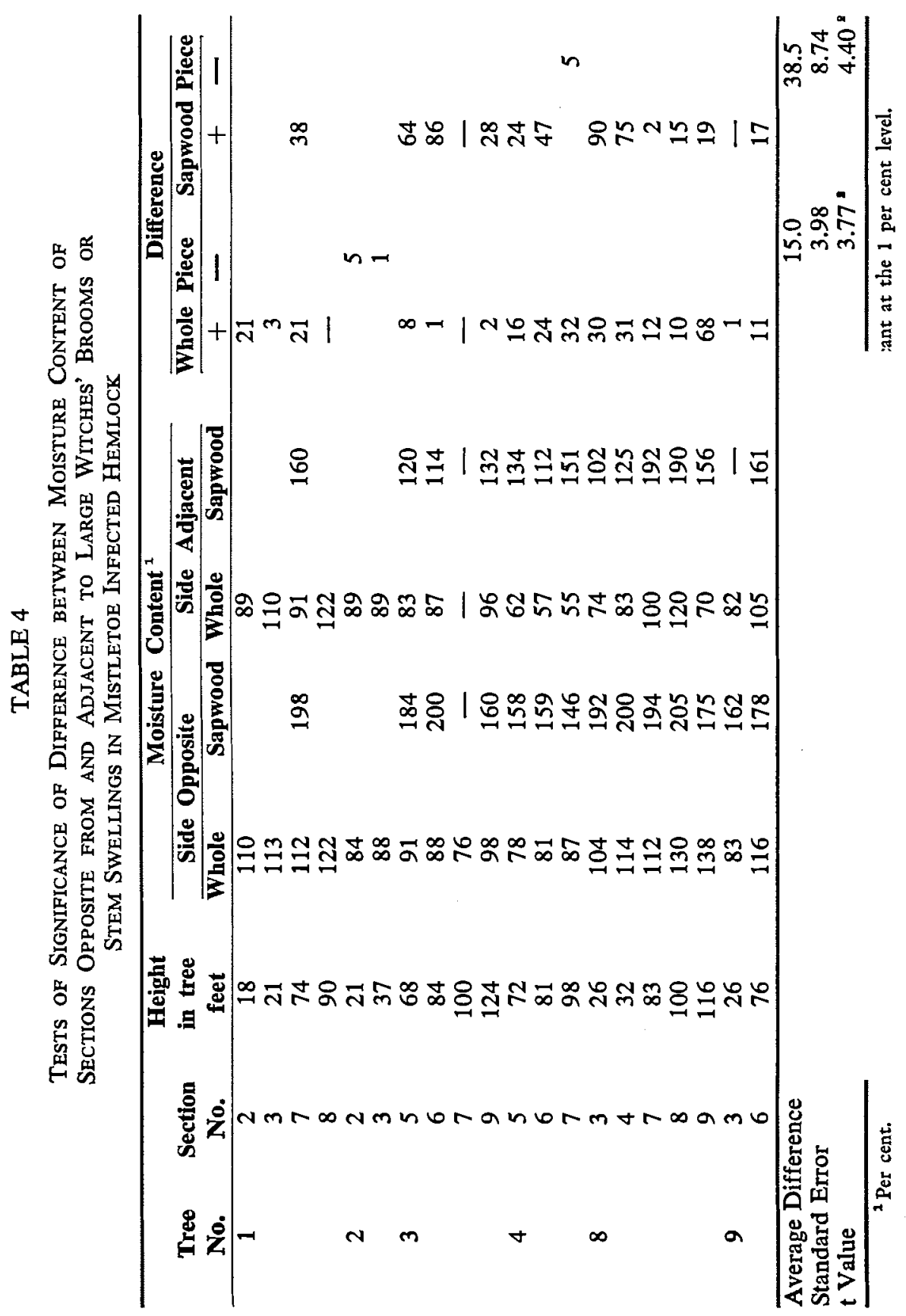



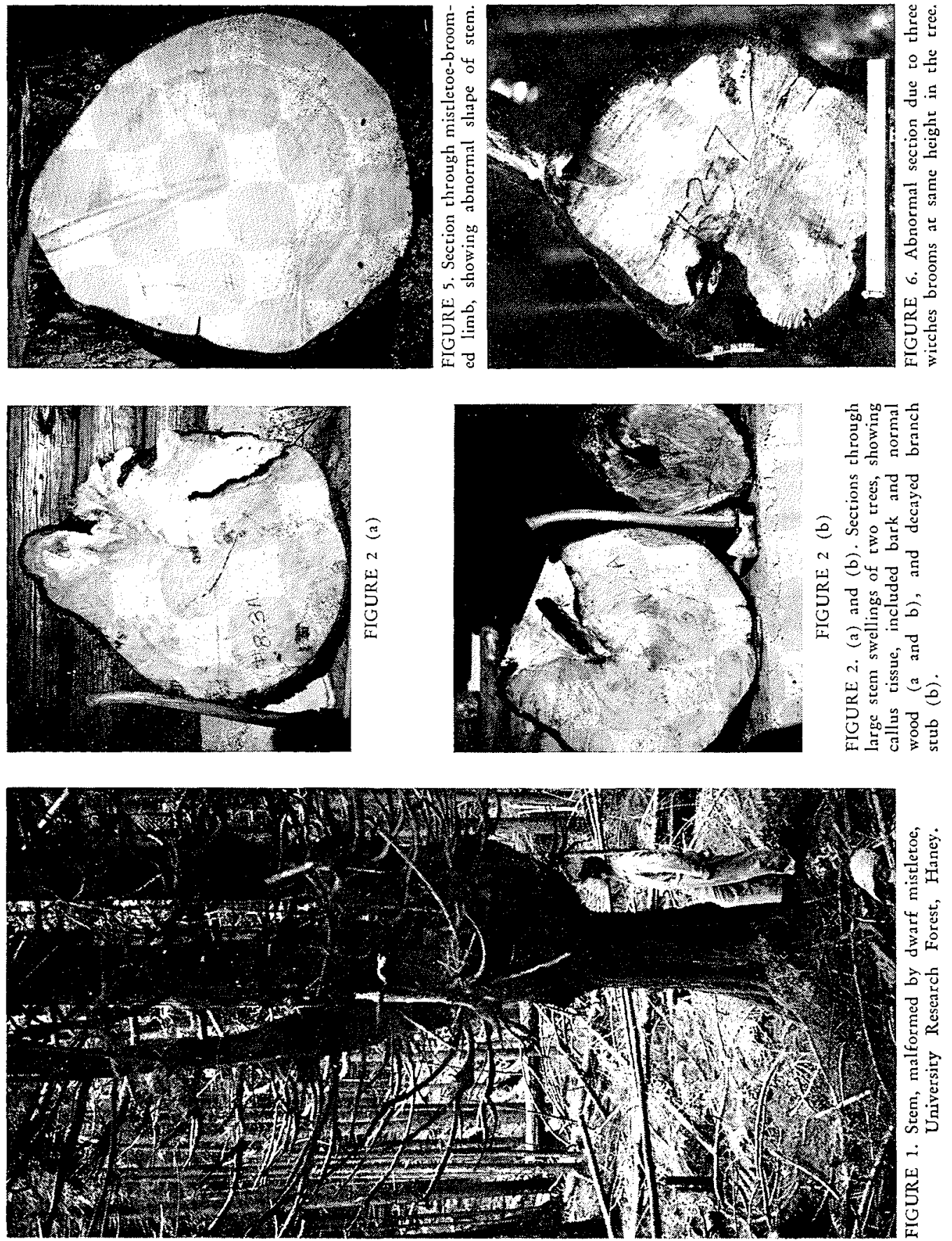


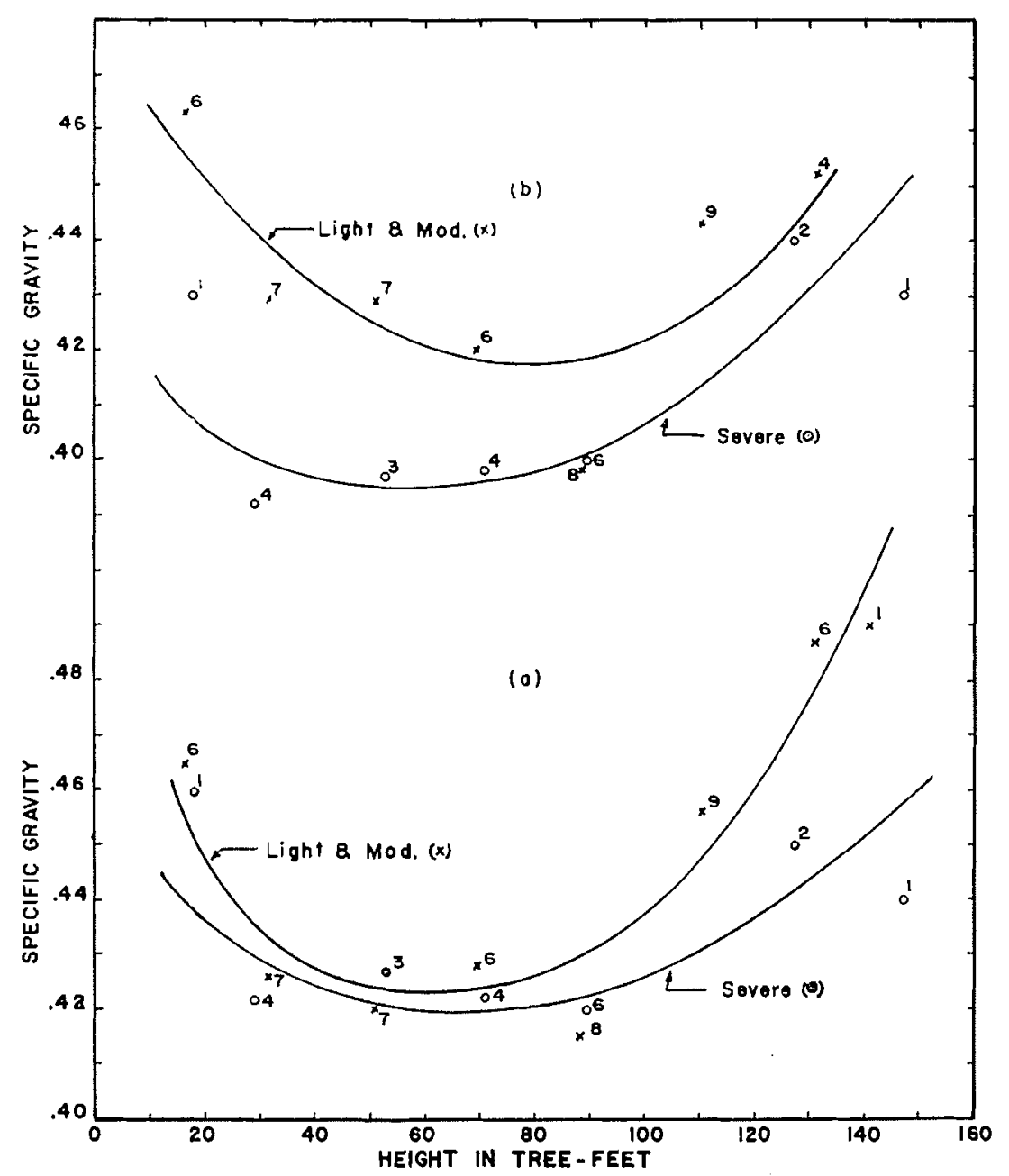

Fig. 7. Specific grovity af (a) stem sectlons, and (b) sopwood soctions, at various helghts in the stem for comblned doto of light and moderote infection, and severe infection, with hemlock mistletoe. 
SEPTEMBER, 1956

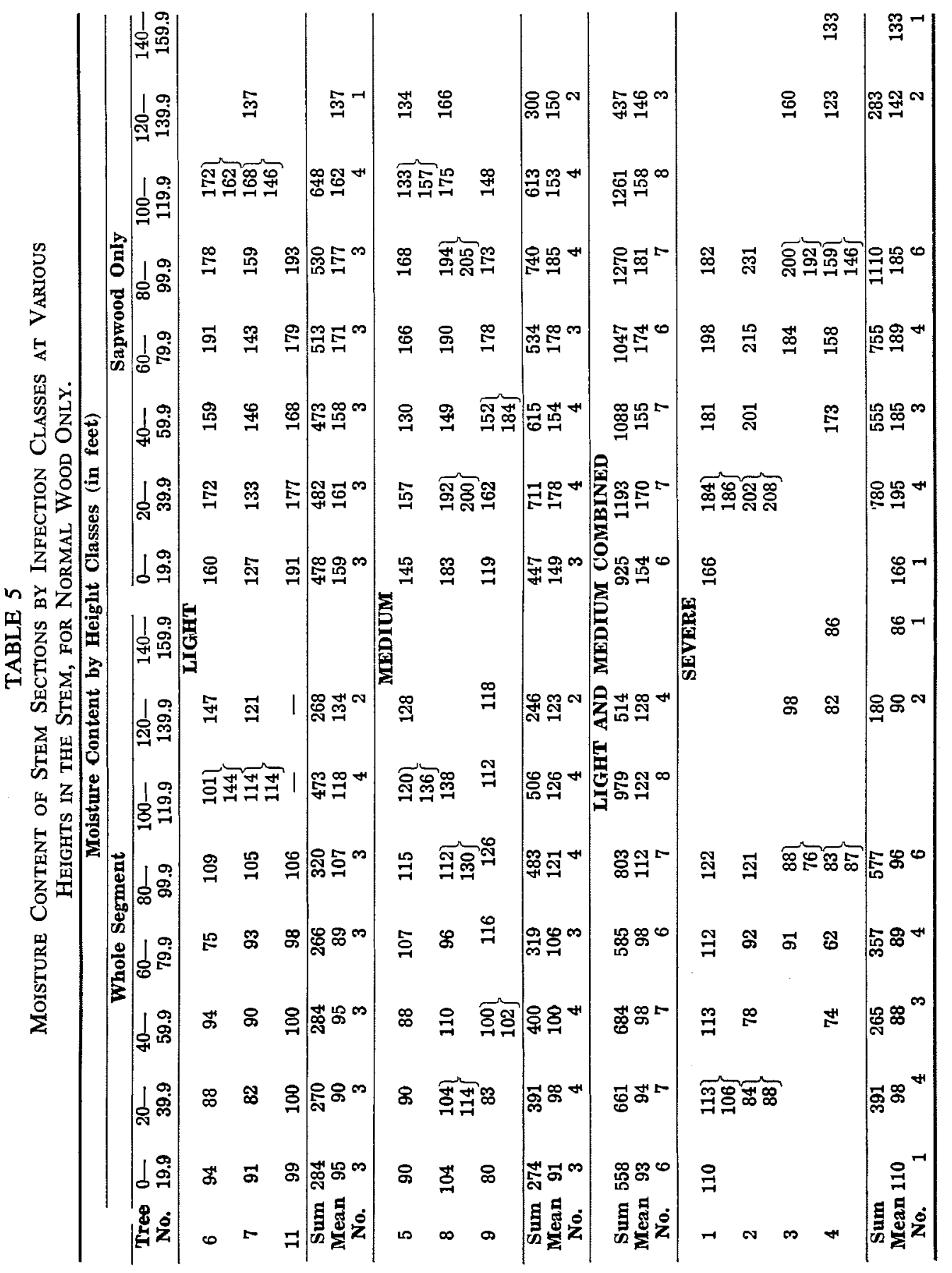




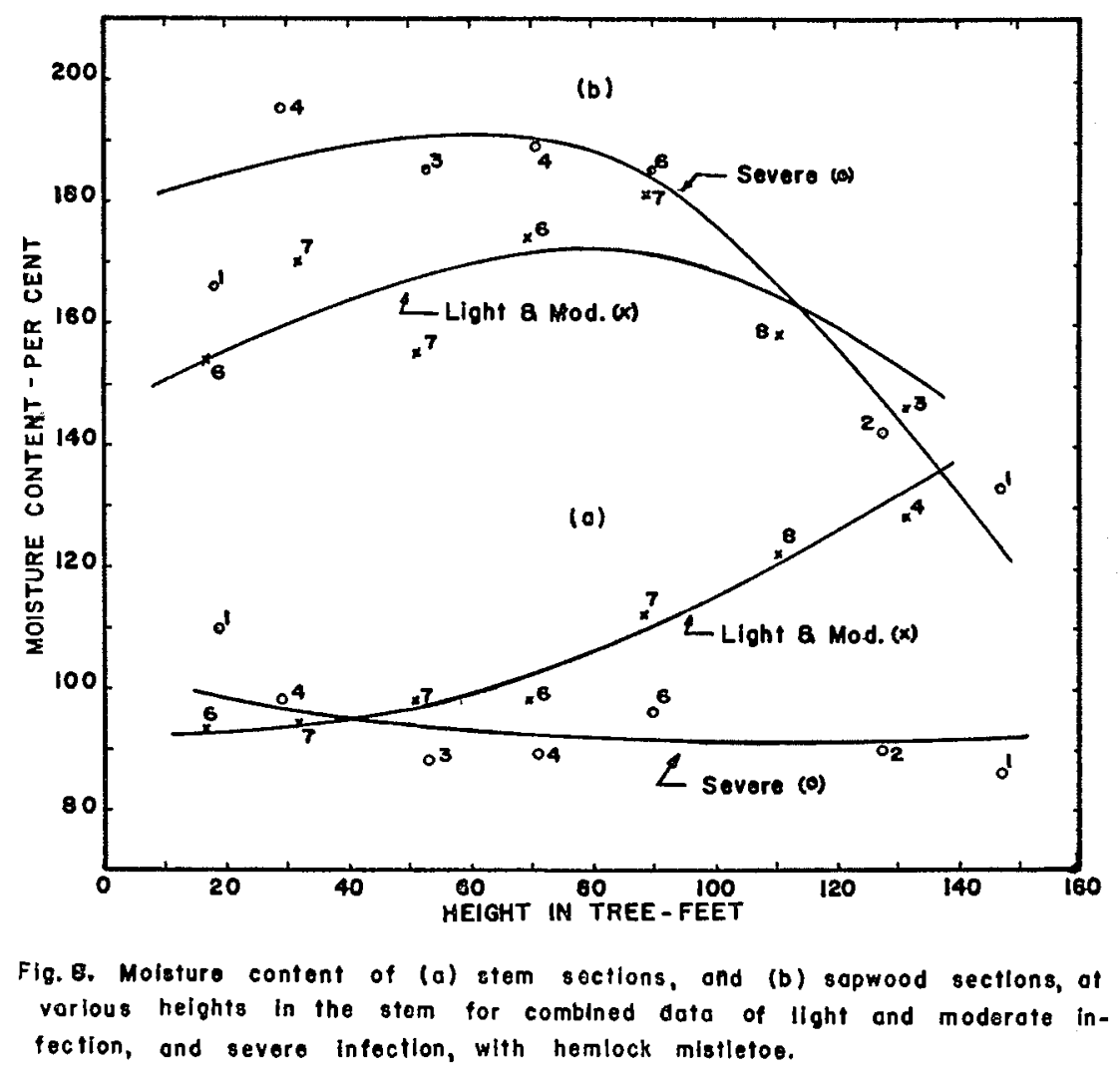

The reduction in moisture content along with specific gravity would cause such logs to float better, but has no other practical significance.

(d) A definite but unmeasured reduction would occur in lumber yield and value as a result of:

(i) swellings which produce abnormal tissue;

(ii) large and extremely hard knots from limbs that support or have supported witches' brooms. Such knots will remain intergrown for a much longer period than normal knots;

(iii) decay, which enters the tree at cankerous zones.

(e) Results merely indicate trends or conditions. A much larger sample would be required to establish definite relationships.

\section{REFERENCES}

1. BARNES, G. H. 1949. Site classification of even-aged stands of western hemlock. Research Note No. 50, Pacific Northwest Forest and Range Experiment Station.

2. BOYCE, J. S. 1948. Forest pathology. Ed. 2; p. 550. McGraw-Hill Book Company, Inc. New York.

3. BUCKLAND, D. C. and E. G. MARPLES. 1952. Management of western hemlock infested with dwarf mistletoe. Brit. Col. Lumberman 36 (5): 50, 51, 136, 138, 140. May. 